Discussion Paper No. 856

\title{
DIFFERENCE OR RATIO: \\ IMPLICATION OF STATUS PREFERENCE ON STAGNATION
}

\author{
Yoshiyasu Ono \\ Katsunori Yamada
}

October 2012

Revised March 2013

The Institute of Social and Economic Research

Osaka University

6-1 Mihogaoka, Ibaraki, Osaka 567-0047, Japan 
March 2013

\title{
Difference or Ratio:
}

\section{Implications of Status Preference on Stagnation*}

\author{
by \\ Yoshiyasu Ono ${ }^{\dagger}$ and Katsunori Yamada ${ }^{\ddagger}$
}

\begin{abstract}
We consider a dynamic macroeconomic model of households that regard relative affluence as social status. The measure of relative affluence can be the ratio to, or the difference from, the social average. The two specifications lead to quite different results: under the ratio specification full employment is necessarily realized, whereas under the difference specification there is a case where a persistent shortage of aggregate demand arises. Affluence comparison experiments provide empirical indications that the difference specification is far more persuasive than the ratio specification. Therefore, persistent stagnation may well occur.
\end{abstract}

JEL classification: C91, E12, E24

Keywords: status, stagnation, unemployment.

* Permission by Masayuki Sato for usage of the data set originally used in Yamada and Sato (2010) is greatly appreciated. This research is financially supported by a Grant-in-Aid for Scientific Research from the Japan Society for the Promotion of Science (JSPS).

${ }^{\dagger}$ Institute of Social and Economic Research, Osaka University. Adress: 6-1 Mihogaoka, Ibaraki, Osaka 567-0047, Japan. E-mail: ono@iser.osaka-u.ac.jp

$\ddagger$ Institute of Social and Economic Research, Osaka University and MOVE Universitat Autonoma de Barcelona. Adress: 6-1 Mihogaoka, Ibaraki, Osaka 567-0047, Japan. E-mail: kyamada@iser.osaka-u.ac.jp 


\section{Introduction}

Stagnation in the wake of the 2008 international financial crisis has spread worldwide. Japan has suffered from serious stagnation for more than two decades since its asset bubble burst in 1990. Facing such dire economic circumstances, economists now more than ever need an analytical framework that can treat inefficient macroeconomic outcomes and valid policy options for recovery from chronic stagnation. The currently dominant research agenda for dealing with stagnation is the New Keynesian approach promoted by researchers such as Christiano et al. (2005) and Blanchard and Galí (2007), who develop microeconomic foundations of price sluggishness to analyze macroeconomic fluctuations. This type of analysis, however, treats not chronic stagnation but rather short-run recessions that fade out as prices adjust.

Ono (1994, 2001) first explored persistent stagnation in a dynamic optimization framework, in the spirit of Chapter 17 of Keynes's General Theory. Households in this model have an insatiable preference for money, which yields a liquidity trap. Prices continue to adjust, but nevertheless shortages of aggregate demand and employment appear in the steady state. Murota and Ono (2011) also presented a model of persistent stagnation in which status preference plays the same role in creating persistent stagnation as does the insatiable preference for money. They considered three objects of status preference-consumption, physical capital holding, and money holding — and found that an economy grows or stagnates depending on which is the primary measure of status. If it is money (an unproducible asset), persistent stagnation with unemployment occurs.

The above-mentioned insatiable desires for absolute and relative money holdings were discussed by Keynes (1972, p. 326). He wrote: "Now it is true that the needs of human beings may seem to be insatiable. But they fall into two classes - those needs which are absolute in the sense that we feel them whatever the situation of our fellow human beings may be, and those which are relative in the sense that we feel them only if their satisfaction lifts us above, makes us feel superior to, our fellows." It may, however, be ambiguous whether the target of people's desire is to hold money or wealth. In the recent literature of status preferences, such as Corneo and Jeanne (1995) and Futagami and Shibata (1998), status concerns are often defined with respect to wealth holdings. 
Following this convention, we present a model with status preference for wealth and explore the possibility of persistent stagnation. In this analysis there are two specifications of social status. One is that people care about the difference of their wealth holdings from the social average. The other is that people care about the ratio to the social average. ${ }^{1}$ Murota and Ono assumed that people care about the difference of money holdings because this specification is necessary for persistent stagnation to occur. Corneo and Jeanne (1995) and Futagami and Shibata (1998) took the ratio as the measure of status because that specification is required for endogenous growth to occur in their models. ${ }^{2}$ We examine both cases and find that persistent stagnation occurs under the difference specification but not under the ratio specification. Thus, the difference specification is indispensable for our model to treat persistent stagnation.

We empirically examine the two specifications to see which is more plausible. Data are borrowed from the hypothetical discrete choice experiment on income comparisons of Yamada and Sato (2010). Following Train (2009), we apply the random utility model framework to the analysis. While this framework is mostly used for parameter estimation of utility functions, we instead conduct a horse race between the two specifications and apply the Akaike Information Criteria (AIC) to the comparison. We find that the difference specification fits the data much better than the ratio specification does, theoretically indicating persistent stagnation.

\section{Two Specifications of Status Concern}

We consider a representative household that cares about social status, whose utility is

$$
\int_{0}^{\infty}[u(c)+v(m)+\sigma(a, \bar{a})] \exp (-\rho t) d t
$$

where $u(c)$ is the utility of consumption $c, v(m)$ is the utility of money $m$ for transactions, $\sigma(a, \bar{a})$ represents status preference, $a$ is total asset holdings, and $\bar{a}$ is the social average of $a$. Functions $u(c)$ and $v(m)$ satisfy

\footnotetext{
${ }^{1}$ Clark and Oswald (1998) considered both the difference and ratio specifications of social status and explored tax policy implications for both cases in a static setting.

${ }^{2}$ Under the difference specification and decreasing returns to real capital, Murota and Ono (2011) showed that endogenous growth occurs when households regard real capital as status.
} 


$$
\begin{gathered}
u^{\prime}(c)>0, u^{\prime \prime}(c)<0, u^{\prime}(0)=\infty ; \\
v^{\prime}(m)>0, v^{\prime \prime}(m)<0, v^{\prime}(0)=\infty, v^{\prime}(\infty)=0 .
\end{gathered}
$$

Two types of status preference $\sigma(a, \bar{a})$ are considered. One is that the household cares about the difference (case D), and the other is that it cares about the ratio (case R).

$$
\begin{array}{cc}
\text { Case D: } & \sigma(a, \bar{a})=\sigma_{D}(a-\bar{a}), \quad \sigma_{D}^{\prime}>0 ; \\
\text { Case R: } & \sigma(a, \bar{a})=\sigma_{R}\left(\frac{a}{\bar{a}}\right), \quad \sigma_{R}^{\prime}>0 .
\end{array}
$$

The flow budget equation and the asset budget constraint are respectively

$$
\begin{gathered}
\dot{a}=r a+w x-R m-c-\tau \\
a=m+b,
\end{gathered}
$$

where $r$ is the real interest rate, $w$ is the real wage, $x$ is the amount of employment, $b$ is interest-bearing assets, $R$ is the nominal interest rate, and $\tau$ is a lump-sum tax. Obviously $R$ satisfies

$$
R=r+\pi
$$

where $\pi$ is the inflation rate. Maximizing (1) subject to (4) gives a Ramsey equation and portfolio choice summarized as

$$
\rho+\eta \frac{\dot{c}}{c}+\pi=R+\frac{\sigma_{a}(a, \bar{a})}{u^{\prime}(c)}=\frac{v^{\prime}(m)+\sigma_{a}(a, \bar{a})}{u^{\prime}(c)}
$$

where

$$
\eta=-u^{\prime \prime}(c) c / u^{\prime}(c), \quad \sigma_{a}(a, \bar{a})=\frac{\partial \sigma(a, \bar{a})}{\partial a} .
$$

The transversality condition is

$$
\lim _{m \rightarrow \infty} u^{\prime}(c)(m+b) e^{-\rho t}=0 .
$$

The number of households is normalized to unity, so the amount of employment $x$ straightforwardly represents the employment rate.

The firm sector uses only labor to produce a commodity with linear technology $\theta x$, where $\theta$ is the labor productivity and is assumed to be constant. In this case, the firm sector infinitely expands production if nominal commodity price $P$ exceeds nominal wage $W$, but 
produces nothing if $W$ exceeds $P$. Thus, with perfect flexibility of $P, P$ takes the value that satisfies

$$
\frac{W}{P}=w=\theta
$$

as long as a finite and positive amount of the commodity is traded. Since the profits in this case are zero, the firm value equals zero. Therefore, interest-bearing assets $b$ consist of only government bonds.

In the money market,

$$
\frac{M}{P}=m
$$

where $M$ is the nominal money stock. The monetary authority is assumed to keep $M$ constant for simplicity, and thus

$$
\frac{\dot{m}}{m}=-\pi
$$

The fiscal authority finances interest payments $r b$ by collecting tax $\tau$ and issuing new bonds. ${ }^{3}$ Formally,

$$
\dot{b}+\tau=r b
$$

The fiscal authority adjusts $\dot{b}$ and $\tau$ so that the no-Ponzi-game condition is satisfied.

Due to the perfect flexibility of $P$ in the commodity market,

$$
c=\theta x .
$$

If $W$ is also perfectly flexible,

$$
x=1 .
$$

Substituting (8), (10) and (11) into (5) yields

$$
\dot{m}=\left(\rho-\frac{v^{\prime}(m)+\sigma_{a}(a, \bar{a})}{u^{\prime}(\theta)}\right) m .
$$

Since $a=\bar{a}=m+b$, from (3) $\sigma_{a}(a, \bar{a})$ satisfies

$$
\text { Case D: } \quad \sigma_{a}(a, \bar{a})=\sigma_{D}^{\prime}(0),
$$

\footnotetext{
${ }^{3}$ We ignore government purchases, for simplicity, but even when government purchases are considered the arguments presented are essentially the same.
} 


$$
\text { Case R: } \quad \sigma_{a}(a, \bar{a})=\frac{\sigma_{R}^{\prime}(1)}{m+b} \text {. }
$$

Equation (12) has the same structure as the dynamics of the standard money-in-the-utilityfunction model (Blanchard and Fischer, 1989, pp. 239-243), and thus $P$ initially jumps to the level that makes $m$ satisfy

$$
\begin{aligned}
& \text { Case D: } \quad c=\theta, \frac{v^{\prime}(m)+\sigma_{D}^{\prime}(0)}{u^{\prime}(\theta)}=\rho, \\
& \text { Case R: } \quad c=\theta, \frac{v^{\prime}(m)+\frac{\sigma_{R}^{\prime}(1)}{m+\bar{b}}}{u^{\prime}(\theta)}=\rho,
\end{aligned}
$$

where $\bar{b}$ implies the steady-state level of $b$ that the fiscal authority determines, and the steady state is immediately reached. However, this state may not exist as shown below.

In case R, the value of $m$ that satisfies (14) definitely exists, since from (2)

$$
\lim _{m \rightarrow 0} \frac{v^{\prime}(m)+\frac{\sigma_{R}^{\prime}(1)}{m+\bar{b}}}{u^{\prime}(\theta)}(=\infty)>\rho>\lim _{m \rightarrow \infty} \frac{v^{\prime}(m)+\frac{\sigma_{R}^{\prime}(1)}{m+\bar{b}}}{u^{\prime}(\theta)}(=0) .
$$

Thus, the full-employment steady state is indeed realized. In case $\mathrm{D}$, however, there is no $m$ that satisfies (14) if

$$
\frac{\sigma_{D}^{\prime}(0)}{u^{\prime}(\theta)}>\rho,
$$

since for any $m$

$$
\frac{v^{\prime}(m)+\sigma_{D}^{\prime}(0)}{u^{\prime}(\theta)}>\rho
$$

which is inconsistent with the first equation in (14). Note that if productivity $\theta$ is high or if the status preference $\sigma_{D}^{\prime}(0)$ is strong, (15) is likely to hold. Then the dynamics given by (12) are negative for any positive $m$. Moreover, if

$$
\lim _{m \rightarrow 0} v^{\prime}(m) m>0
$$

it is strictly negative even when $m=0$, implying that $m$ becomes negative within a finite time. ${ }^{4}$ Thus, there is no feasible path.

\footnotetext{
${ }^{4}$ This condition is required to avoid hyperinflationary paths in the standard money-in-the-utility-function model. See Obstfeld and Rogoff (1983) for this property.
} 


\section{Persistent Stagnation under the Difference Specification}

In the previous section, we find that under the difference specification there is no dynamic equilibrium path if (15) holds. In this case, preference for money holding always dominates preference for consumption, which should naturally result in a demand shortage. However, since perfect adjustments of $P$ and $W$ are assumed, no demand shortage is allowed to arise, which may lead to no dynamic equilibrium path being obtained. To take into account the possibility of unemployment due to a demand shortage, we assume sluggish wage adjustment and explore the possibility of persistent stagnation. ${ }^{5}$ Specifically, we adopt the following wage adjustment process:

$$
\frac{\dot{W}}{W}=\alpha(x-1)
$$

where $\alpha$ is the adjustment speed. See Ono and Ishida (2013) for a microeconomic foundation for this type of wage adjustment. ${ }^{6}$

It is noteworthy that recent studies on Phillips curves, such as the New Classical, the New Keynesian, and the hybrid approaches, are not appropriate for the analysis of persistent stagnation because they are set up so that the inflation-deflation rate cumulatively expands as long as market disequilibrium exists. ${ }^{7}$ Thus, the possibility of unemployment in a steady state, which we focus on, is intrinsically eliminated.

From (7) and (16), we find

$$
\pi=\alpha(x-1)
$$

From (4), (5), (8), (9), (10) and the above equation, we obtain

$$
\eta \frac{\dot{c}}{c}=\frac{v^{\prime}(m)+\sigma_{a}(a, \bar{a})}{u^{\prime}(c)}-\rho-\alpha\left(\frac{c}{\theta}-1\right)
$$

\footnotetext{
${ }^{5}$ Obviously, nominal wage sluggishness does not exclude the possibility of full employment in the steady state.

${ }^{6}$ They apply various fairness concepts to the mechanism of nominal wage setting and obtain nominal wage movements that depend on the unemployment rate if unemployment exists. They show that the local dynamics are the same as those with such wage adjustments. They first obtain the dynamics of fair wages as mentioned above, and find that, with unemployment, firms set wages to be the same as fair wages to urge their employees to work efficiently. $1 / \alpha$ is found to be the average duration of employment since wage adjustments are due to alternation of incumbent workers whose fair wages depend on their past, and their rivals', wages by new recruits who have no preconceptions about fair wages. Without unemployment, however, firms set higher wages than the fair wages to aquire more workers, so wages immediately reach equilibrium levels.
}

${ }^{7}$ See Woodford (2003) for properties of those Phillips curves. 


$$
\begin{gathered}
\frac{\dot{m}}{m}=-\pi=-\alpha\left(\frac{c}{\theta}-1\right), \\
\dot{b}=\left[\frac{v^{\prime}(m)}{u^{\prime}(c)}-\alpha\left(\frac{c}{\theta}-1\right)\right] b-\tau,
\end{gathered}
$$

where $\sigma_{a}(a, \bar{a})$ is given by (13). The three equations of (17) formulate a three-dimensional autonomous dynamic system with respect to $c, m$, and $b$. The full-employment steady state given by (14) is eventually reached if it exists. ${ }^{8}$ It indeed does in case R, and in case D where (15) is invalid.

However, if (15) is valid in case D, the steady state with full employment given by (14) does not exist. Then, the first and second equations of (17) form a two-dimensional autonomous dynamic system with respect to $c$ and $m$ :

$$
\begin{gathered}
\eta \frac{\dot{c}}{c}=\frac{v^{\prime}(m)+\sigma_{D}^{\prime}(0)}{u^{\prime}(c)}-\rho-\alpha\left(\frac{c}{\theta}-1\right), \\
\frac{\dot{m}}{m}=-\pi=-\alpha\left(\frac{c}{\theta}-1\right) .
\end{gathered}
$$

Because $W$ cannot jump, $P$ initially takes the value that satisfies (7) for the initial $W$ and determines the initial level of $m$ while $c$ jumps to the amount that is on the saddle path. ${ }^{9} \mathrm{~A}$ demand shortage remains and continues to yield deflation. Eventually, $c$ satisfies

$$
\Phi(c) \equiv \frac{\sigma_{D}^{\prime}(0)}{u^{\prime}(c)}-\left(\rho+\alpha\left(\frac{c}{\theta}-1\right)\right)=0
$$

From (15), one has

$$
\Phi(\theta)=\frac{\sigma_{D}^{\prime}(0)}{u^{\prime}(\theta)}-\rho>0
$$

Therefore, for (19) to have a positive solution, it must be valid that

$$
\Phi(0)=-(\rho-\alpha)<0
$$

and then $c$ satisfies

$$
0<c<\theta
$$

\footnotetext{
${ }^{8}$ The uniqueness and the stability of the present dynamics are proved in the same way as in Ono (1994, 2001), who treats the case where $b=0$.

${ }^{9}$ The dynamic equations given in (18) are mathematically the same as when there is a strictly positive upper bound on the marginal utility of money, as analyzed by Ono (2001). He showed that there is a unique dynamic path and that it converges to the stagnation steady state if (15) and (20) are valid.
} 
which implies a demand shortage in the steady state. Deflation persists, making $m$ diverge to infinity, but nevertheless the transversality condition (6) is valid since

$$
\lim _{m \rightarrow \infty} \frac{\dot{m}}{m}=\rho-\frac{\sigma_{D}^{\prime}(0)}{u^{\prime}(c)}<\rho,
$$

and $b=\bar{b}$. Note that in this state $v^{\prime}(m)=0$, so from the second equation of (5)

$$
R=0
$$

meaning the zero interest rate holds.

Let us now state the economic implications of the difference between the two specifications. In case $\mathrm{R}$, in which households care about the ratio of asset holding compared to the social average, the marginal utility of real balances, represented by $v^{\prime}(m)+\sigma_{R}^{\prime}(1) /(m+b)$, converges to zero as $m$ approaches infinity. Thus, there is a level of $m$ that equalizes the desire to accumulate real balances to the desire to consume so much as to realize full employment. Then, full employment and the steady-state price are obtained. In case $\mathrm{D}$, in which households care about the difference, the desire to accumulate assets $\sigma_{D}^{\prime}(0)$ remains strictly positive. Thus, if (15) holds, no matter how much assets accumulate the desire to accumulate money as an asset will not decrease, so insufficient purchasing power will be directed toward consumption to reach full employment. A demand shortage remains despite continued declining prices and expanding real balances.

\section{Experimental Evidence of the Two Specifications of Status}

In the previous section we showed that persistent stagnation arises when households care about not the ratio of their asset holdings to, but the difference from, the social average. To see relevance to the real world, we investigate which of the two specifications of social status is more plausible.

To do so we use the data set created by the hypothetical discrete choice experiment of Yamada and Sato (2010), which includes 48,172 observations from 10,203 respondents. They conducted an original Internet-based survey in February 2010 with Japanese subjects, and investigated the intensity of income comparisons against the social average. ${ }^{10} \mathrm{By}$

\footnotetext{
${ }^{10}$ By setting up an experiment such that parameters were fully randomized and choice situations were orthogonal, they exploited full potential of the discrete choice experiment framework to find if the subjects have altruism or jealousy. See section 3 of Yamada and Sato (2010) for details of the experimental setting.
} 
applying the data to a random utility model framework, they estimated the following utility function with social status as in Dupor and Liu (2003) and Liu and Turnovsky (2005):

$$
V=V(y, \bar{y})=V\left(\frac{\left(y \bar{y}^{\gamma}\right)^{1-\rho}}{1-\rho}\right)
$$

where $y$ is the subject's income and $\bar{y}^{\gamma}$ is the social average. They found a negative status effect, implying jealousy. With this in mind, we replace (21) by the two utility specifications with a single composite variable, given in (3), so that we can focus on a comparison of the two. We then apply the conditional logit model framework and compare their AICs.

Note that there is a gap between the theoretical structure in the previous section and the experimental setting given below. In the choice experiment of Yamada and Sato (2010), the relative concern is associated with income, whereas in the present theory it is with asset holdings. However, income is a predictor of asset holdings under the permanent income hypothesis. Moreover, Headey and Wooden (2004) found that income and asset holdings are both important determinants of happiness, and that the positive effect of asset holdings on happiness is taken away by the income term when both are taken into account in the regression. This implies that income is a good proxy for asset holdings in the happiness analysis. Therefore, we take income $y$ as a proxy for assets $a$ and replace $\sigma(a, \bar{a})$ given in (3) by $\sigma(y, \bar{y})$.

Let us reformulate the model to the following random utility model:

$$
\sigma\left(y_{i}, \bar{y}_{i}\right)=\beta X_{i}+C+\epsilon_{i}
$$

where $i$ represents each income scenario, $X_{i}$ is

$$
\begin{array}{ll}
\text { In case D: } & X_{i}=y_{i}-\bar{y}_{i}, \\
\text { In case R: } & X_{i}=\frac{y_{i}}{\bar{y}_{i}},
\end{array}
$$

$\beta$ is the marginal utility from the status, $C$ is the constant term, and $\epsilon$ is the error term, which follows an independent and identical distribution of extreme value type 1 (IIDEV1). The probability $p_{i j}$ that respondents prefer income situation $i$ to income situation $j$ is given by

$$
p_{i j}=\operatorname{Prob}\left(\sigma\left(y_{i}, \bar{y}_{i}\right)>\sigma\left(y_{j}, \bar{y}_{j}\right)\right), \text { for all } i \neq j .
$$

By assuming IIDEV1 for the error term we consider a conditional logit model (McFadden, 1974) and estimate the parameter vector $\beta$ of the random utility function using the maximized likelihood method. We also assume that irrelevant alternatives are independent 
(IIA), and that the random components of each alternative and those within each subject are respectively uncorrelated.

The first and second rows in Table 1 show the results under the ratio and difference specifications, respectively. In both cases, the relative income terms, $y_{i}-\bar{y}_{i}$ and $y_{i} / \bar{y}_{i}$, have a positive and significant effect, which suggests that the comparison effect is not so strong as to validate the Easterlin paradox (Easterlin 1974). The striking finding here is a significant difference in the AIC between the two specifications. The AIC under the difference specification is much smaller than that under the ratio specification. Also, the pseudo R-squared for the difference specification has a high value of 0.22 in a nonlinear model, while that for the ratio specification is 0.0053 . Therefore, the difference specification is much more plausible than the ratio specification.

Table 1: Estimation results from the conditional logit model

\begin{tabular}{cccccc}
\hline \hline Dep var: Utility & \multicolumn{2}{c}{ Relative income } & Pseudo R2 & AIC & N \\
& Sign & robust s.e. & & & \\
\hline Ratio & $0.4430^{* * *}$ & $(0.1059)$ & 0.0053 & 63261.28 & 48172 \\
Difference & $0.0337 * * *$ & $(0.0004)$ & 0.2255 & 51721.87 & 48172 \\
\hline
\end{tabular}

Robust standard errors clustered by subjects, $* * * p<0.01$.

As shown in section 3, the difference specification results in persistent stagnation. Under the ratio specification, however, full employment is necessarily attained in the steady state. Our experimental results strongly support the former; hence we may conclude that the present model provides a theoretical framework for analyzing persistent stagnation and unemployment.

\section{Conclusion}

When relative affluence compared to the social average is taken as status, the measure can be the ratio to, or the difference from, the social average. The two specifications lead to mutually quite different scenarios of business activity. If it is the ratio, full employment is necessarily reached in the steady state. If it is the difference, there is a case where unemployment and stagnation due to shortage of aggregate demand are the result in the 
steady state. This case arises particularly if the output capacity is high or if the status preference is strong.

Using the data of the experiment of affluence comparison carried out by Yamada and Sato (2010), we find that the difference specification fits the data far better than the ratio specification does. Our model can thus be applied to analyze persistent stagnation, such as Japan has been experiencing for two decades. Furthermore, since the mathematical structure of the present model is essentially the same as that of Ono $(1994,2001)$, the same policy implications as those of Ono hold. They are quite different from those under the conventional models and are more in conformity with Keynes (1936): an increase in government purchases expands private consumption, while faster the wage adjustments and higher productivity reduce private consumption and worsen stagnation.

\section{References}

Blanchard Olivier J., and Stanley Fischer (1989), Lectures on Macroeconomics, Cambridge, MA: MIT Press.

Blanchard, Olivier J., and Jordi Galí (2007), "Real Wage Rigidities and the New Keynesian Model", Journal of Money, Credit and Banking, Vol. 39, pp. 35-65.

Christiano, Lawrence, Martin Eichenbaum and Charles Evans (2005), "Nominal Rigidities and the Dynamic Effects of a Shock to Monetary Policy", Journal of Political Economy, Vol. 113, pp. 1-45.

Clark, Andrew E., and Andrew J. Oswald (1998), "Comparison-concave utility and following behaviour in social and economic settings", Journal of Public Economics, Vol. 70, pp. 133-155.

Corneo, Giacomo, and Olivier Jeanne (1997), "On Relative Wealth Effects and the Optimality of Growth", Economics Letters, Vol. 54, pp. 87-92.

Dupor, Bill, and Wen-Fang Liu (2003), "Jealousy and Equilibrium Overconsumption”, American Economic Review, Vol. 93, pp. 423-428.

Easterlin, Richard. A. (1974), "Does Economic Growth Improve the Human Lot? Some Empirical Evidence,” in Paul A. David and Melvin W. Reder., eds., Nations and Households in Economic Growth: Essays in Honour of Moses Abramowitz, New York: Academic Press. 
Futagami, Koichi, and Akihisa Shibata (1998), "Keeping One Step Ahead of the Joneses:

Status, the Distribution of Wealth, and Long Run Growth", Journal of Economic Behavior and Organization, Vol. 36, pp. 109-126.

Headey, Bruce, and Mark Wooden (2004), "The Effects of Wealth and Income on Subjective Well-Being and Ill-Being”, Melbourne Institute Working Paper Series wp2004n03, Melbourne Institute of Applied Economic and Social Research, The University of Melbourne.

Keynes, John M. (1972), "Economic Possibilities for Our Grandchildren”, in Essays in Persuasion, The Collected Writings of John Maynard Keynes, Vol. IX, London: Macmillan, pp. 321-332. Originally published in 1930.

Keynes, John M. (1936), The General Theory of Employment, Interest and Money, London: Macmillan.

Liu, Wen-Fang, and Stephen J. Turnovsky (2005), “Consumption externalities, production externalities, and long-run macroeconomic efficiency", Journal of Public Economics, Vol. 89, pp. 1097-1129.

McFadden, Daniel (1974), “Conditional Logit Analysis of Qualitative Choice Behavior”, in Paul Zarembka, ed., Frontiers in Econometrics, New York: Academic Press.

Murota, Ryuichiro, and Yoshiyasu Ono (2011), "Growth, Stagnation and Status Preference”, Metroeconomica, Vol. 62, pp. 112-149.

Obstfeld, Maurice, and Kenneth Rogoff (1983), "Speculative Hyperinflations in Macroeconomic Models: Can We Rule Them Out?", Journal of Political Economy, Vol. 91, pp. 675-687.

Ono, Yoshiyasu (1994), Money, Interest, and Stagnation - Dynamic Theory and Keynes's Economics, Oxford University Press.

Ono, Yoshiyasu (2001), “A Reinterpretation of Chapter 17 of Keynes's General Theory: Effective Demand Shortage under Dynamic Optimization”, International Economic Review, Vol. 42, pp. 207-236.

Ono, Yoshiyasu, and Jun'ichiro Ishida (2013), “On Persistent Demand Shortages: A Behavioral Approach", Japanese Economic Review, forthcoming. A revised version of "Nominal Wage Adjustment, Demand Shortage and Economic Policy", ISER Discussion Papers No. 760, Institute of Social and Economic Research, Osaka University, 2009. 
Train, Kenneth E. (2009), Discrete Choice Methods with Simulation, 2nd edition, Cambridge: Cambridge University Press.

Woodford, Michael (2003), Interest and Prices, Princeton: Princeton University Press.

Yamada, Katsunori, and Masayuki Sato (2010), "Another Avenue for Anatomy of Income Comparisons: Evidence from Hypothetical Choice Experiments", Journal of Economic Behavior and Organization, forthcoming. A revised version of ISER Discussion Papers No. 795, Institute of Social and Economic Research, Osaka University. 